\title{
ISR elicitada en plantas de maní por compuestos secretados por bacterias del género Bacillus
}

Tonelli, María L*., Guerra, Ayelén, Fabra, Adriana.

Departamento de Ciencias Naturales. Facultad de Ciencias Exactas, Físico-Químicas y Naturales. Universidad Nacional de Río Cuarto.*E-mail: mtonelli@exa.unrc.edu.ar.

Introducción: Las enfermedades causadas por hongos limitan la producción del cultivo de maní (March, 2001). Algunas bacterias que controlan o inhiben la actividad de fitopatógenos poseen la capacidad de inducir la resistencia sistémica (ISR) en plantas (Kloepper y col., 1992; Glick, 2012). La ISR se caracteriza por un incremento de la capacidad de defensa en plantas que son apropiadamente estimuladas y luego desafiadas con un fitopatógeno ("priming").En nuestro laboratorio hemos demostrado que los aislamientos nativos Bacillus sp. CHEP5, SEHEP4 y BTEP20 disminuyen la incidencia de marchitamiento por hongo blanco causada por Sclerotium rolfsii en maní, y que secretan al sobrenadante de cultivo lipopéptidos que pueden estar involucrados en la inducción de la respuesta de defensa vegetal.El objetivo de este trabajo fue comprobar la capacidad de inducir resistencia sistémica en maní de los compuestos secretados por dichas bacterias al medio de cultivo.

Materiales y Métodos:Las raíces de maní se inocularon con el sobrenadante de cultivo en medio Landy (Landy, 1948) (que favorece la producción de lipopéptidos) de las bacterias biocontroladoras. Luego de una semana, se inoculó S. rolfsii en la corona de las raíces (asegurando la separación física con el sitio de inoculación del sobrenadante bacteriano). A los 12 días post-inoculación del fitopatógeno, se evaluó el porcentaje de plantas enfermas (incidencia) y el peso seco aéreo en dichas plantas (severidad de la enfermedad). Como marcadores de la ISR, se midió, en plantas inoculadas con los sobrenadantes y/o desafiadas con el fitopatógeno, la actividad de la enzima peroxidasa (Sosa-Alderete, 2009) y la producción de compuestos fenólicos (Ainsworth y Gillespie, 2007) a las 24 h y a las 72 hpi de $S$. rolfsii .Los experimentos se repitieron 3 veces con un $n=5$ cada uno de ellos y los datos se analizaron estadísticamente utilizando ANOVA comparando las medias con un nivel de significancia del 5\% de acuerdo a la prueba de LSD-Fisher.

Resultados:Se demostró una disminución en la incidencia de la enfermedad en plantas inoculadas con los sobrenadantes de cultivo de Bacillus sp. CHEP5, Bacillus sp. SEHEP4 y Bacillus sp. BTEP20 en comparación con las desafiadas sólo con el patógeno (del 50\%, 40\% y 10\%, respectivamente). El peso seco de la parte aérea de las plantas no reflejó, al tiempo en que fue determinado un mejor estado fisiológico de las plantas como consecuencia de la disminución en la severidad de la enfermedad.

A las 24 hpi de $S$. rolfsii, se registró un incremento significativo en la actividad de la enzima peroxidasa solo en las plantas inoculadas con el sobrenadante de Bacillus sp. CHEP5 y desafiadas con el fitopatógeno, mientras que a las $72 \mathrm{hpi}$ del fitopatógeno la producción de compuestos fenólicos se vio incrementada en plantas inoculadas con el sobrenadante de Bacillus sp. CHEP5 o de Bacillus sp. SEHEP4 en comparación con las inoculadas solamente con S. rolfsii (Tabla1).

Tabla 1.Actividad peroxidasa y producción de compuestos fenólicos en plantas inoculadas con sobrenadantes de Baillus sp. yS. rolfsii

\begin{tabular}{|l|c|c|}
\hline \multicolumn{1}{|c|}{ Tratamientos } & $\begin{array}{c}\text { Actividad Peroxidasa } \\
\text { (Unidades de PX/mg de proteínas) }\end{array}$ & $\begin{array}{c}\text { Compuestos fenólicos totales } \\
\text { (mg Ácido gálico/g de peso } \\
\text { fresco) }\end{array}$ \\
\hline Control & $2,26 \pm 1,15^{\mathrm{A}}$ & $437,13 \pm 82,43^{\mathrm{A}}$ \\
\hline S. rolfsii & $7,06 \pm 1,41^{\mathrm{CD}}$ & $654,42 \pm 67,30^{\mathrm{ABC}}$ \\
\hline Bacillus sp. CHEP5-S. rolfsii & $7,59 \pm 1,15^{\mathrm{E}}$ & $844,79 \pm 82,43^{\mathrm{CD}}$ \\
\hline Bacillus sp. SEHEP4-S.rolfsii & $3,01 \pm 0,89^{\mathrm{AB}}$ & $824,26 \pm 53,29^{\mathrm{CD}}$ \\
\hline Bacillus sp. BTEP20-S. rolfsii & $5,9 \pm 1,15^{\mathrm{BCD}}$ & $558,19 \pm 82,43^{\mathrm{ABC}}$ \\
\hline
\end{tabular}

Los valores representan la media \pm E.E de dos repeticiones, cada una con $n=5$. Las letras distintas indican diferencias significativas de acuerdo la prueba de LSD Fisher $(\mathrm{p}<0,05)$.

\section{Conclusiones:}

-Los sobrenadantes de cultivo de cepas nativas de suelos maniseros del Género Bacillus indujeron sistémicamente la respuesta de defensa en plantas de maní, disminuyendo la incidencia del marchitamiento causado por el fitopatógeno $S$. rolfsii.

-La actividad de la enzima peroxidasa mostró ser un marcador molecular que refleja la sensibilización o "priming" de la respuesta de defensa en maní inducidas por metabolitos secretados en el sobrenadante de cultivo de Bacillus sp. CHEP5.

-La ISR elicitada por metabolitos secretados al sobrenadante de cultivo de Bacillus sp. CHEP5 y Bacillus sp. SEHEP4, involucraría la vía de síntesis de compuestos fenólicos.

Financiado por: ANPCyT, CONICET, SECyT-UNRC. 